\title{
PENERAPAN METODE FUZZY SUGENO UNTUK MENENTUKAN JALUR TERBAIK MENUJU LOKASI WISATA DI SURABAYA
}

\author{
Muizzatul Mukaromah \\ Fakultas Matematika dan IImu Pengetahuan Alam, Universitas Negeri Surabaya \\ E-mail: muizzatulmukaromah@gmail.com
}

\begin{abstract}
This study aims to determine the best route to tourist sites in Surabaya. An optimal path will be obtained from three path choices. The method used is Sugeno Fuzzy Logic, by obtaining membership degrees with fuzzification and then being applied to the appropriate rules, followed by the deflation process to produce optimal and less optimal output. There are six tourist attractions to be visited including Tugu Pahlawan, Food Junction Pakuwon, Atlantis Land, Surabaya Zoo (KBS), Suroboyo Carnival, and Mangrove. There are three starting points (Surabaya City Hall, Purabaya Terminal, and Tanjung Perak Port). The criteria used in this study are distance to tourist attractions, time taken, and road density. These criteria were chosen based on almost all tourist locations in the city of Surabaya through the crowds along the main city lanes in Surabaya. Data is obtained through google maps by comparing three paths and the optimal path will be determined to be passed to get to tourist attractions in Surabaya. The results of this study obtained six optimal paths from each starting point.
\end{abstract}

Keywords: fuzzy sugeno, the best route, Surabaya tourism

\begin{abstract}
ABSTRAK
Penelitian ini bertujuan untuk menentukan jalur terbaik menuju lokasi wisata di Surabaya. Akan diperoleh jalur optimal dari tiga pilihan jalur. Metode yang digunakan adalah logika fuzzy sugeno, dengan cara mendapatkan derajat keanggotaan dengan fuzzifikasi dan kemudian diimplikasikan ke dalam rute yang sesuai, dilanjutkan proses defuzzfikasi untuk menghasilkan output optimal dan kurang optimal. Terdapat enam tempat wisata yang akan dikunjungi diantaranya Tugu Pahlawan, Food Junction Pakuwon, Atlantis Land, Kebun Binatang Surabaya (KBS), Suroboyo Carnival, dan Mangrove. Ada tiga titik awal (Balaikota Surabaya, Terminal Purabaya, dan Pelabuhan Tanjung Perak). Kriteria yang digunakan pada penelitian ini adalah jarak ke tempat wisata, waktu yang ditempuh, dan kepadatan jalan. Kriteria tersebut dipilih berdasarkan hampir seluruh lokasi wisata yang ada di kota Surabaya melewati keramaian di sepanjang jalur utama kota yang ada di Surabaya. Data diperoleh melalui Google maps dengan membandingkan tiga jalur dan akan ditentukan jalur optimal yang akan dilewati untuk menuju tempat wisata di Surabaya. Hasil dari penelitian ini diperoleh enam jalur yang optimal dari setiap titik awal.
\end{abstract}

Kata kunci: fuzzy sugeno, rute terbaik, wisata Surabaya 
Surabaya merupakan ibu kota Provinsi Jawa Timur yang memiliki julukan sebagai Kota Pahlawan dan memiliki berbagai macam tempat destinasi wisata. Terdapat berbagai macam destinasi wisata yang begitu menarik mulai dari wisata alam, wisata air, dan berbagai wisata lainnya yang ada di Surabaya beberapa tempat wisata yang ada di Kota Surabaya diantaranya adalah Tugu Pahlawan, Wisata Atlantis Land Surabaya, kebun binatang Surabaya, Food Junction Pakuwon, Suroboyo Carnival, Mangrove, dan lain sebagainya.

Walaupun terkenal dengan udaranya yang begitu panas, tidak menghalangi niat wisatawan untuk menghabiskan masa liburannya di Kota Pahlawan. Di setiap tahunnya terjadi peningkatan wisatawan yang berkunjung ke Surabaya, baik wisatawan dari dalam kota dan luar kota Surabaya. Peningkatan kunjungan wisatawan menyebabkan jalur-jalur menuju lokasi wisata menjadi sangat padat sehingga mengakibatkan kemacetan yang cukup parah terutama pada akhir pekan dan musim liburan.

Kepadatan lalu lintas selalu menjadi penghalang untuk wisatawan menuju objek wisata. Karenanya dibutuhkan sebuah aplikasi dalam pemilihan jalur terbaik yang akan memudahkan wisatawan untuk menuju lokasi wisata yang ada di Surabaya. Google map telah menyediakan jalurjalur terbaik yang harus dilewati namun belum memberikan keputusan yang optimal, Google map memberikan jalur terbaik hanya pada panjang jalan yang harus dilewati, sedangkan informasi tentang kepadatan jalan tidak tersedia.

Maps adalah teknologi pemetaan berbasis web yang menampilkan citra satelit beresolusi tinggi yang digunakan untuk peta jalan. Di dalam aplikasi maps juga terdapat untuk rute sepeda, pejalan kaki, mobil serta penentuan lokasi bisnis di kota-kota berbagai negara seluruh dunia yang di sediakan oleh DigitalGlobe dengan satelitnya QuickBird, serta data dari Geographic Information System (GIS) buatan Tele Atlas, NAVTEQ, dan MapABC. Sedangkan Google maps API adalah fasilitas akses yang diberikan Google kepada para pengembang web yang ingin mengaplikasikan Google maps ke dalam situs yang mereka buat secara gratis (Kurnia \& Kesumaningtyas, 2017).

Penelitian ini menggunakan metode fuzzy sugeno. Sugeno Model Fuzzy Inference Systems diperkenalkan oleh Takagi, Sugeno, dan Kang atau sering disebut TSK. Fuzzy Inference Systems (FIS) didasarkan pada tiga komponen yaitu memerintah dasar, database, dan mekanisme penalaran. Dasar aturan terdiri dari anteseden dan konsequent dari bentuk berikut: Jika A adalah antecedent maka B adalah consequent (Samita, Bihari, \& Samanta, 2018).

Logika fuzzy merupakan metodologi sistem kontrol pemecahan masalah, yang cocok untuk diimplementasikan pada sistem, mulai dari sistem yang sederhana, sistem kecil, embedded system, jaringan PC, multichannel atau workstation berbasis akuisisi data dan sistem kontrol (penerapan logika fuzzy). Logika fuzzy nilai keanggotaan berada di antara 0 dan 1. Artinya, bisa saja suatu keadaan mempunyai dua nilai "Ya" dan "Tidak" secara bersamaan, namun besar nilainya tergantung pada bobot keanggotaan yang dimilikinya (Bahroini, Farmadi, \& Nugroho, 2016)

Pada prinsipnya himpunan fuzzy adalah perluasan himpunan crisp, yaitu himpunan yang membagi sekelompok individu ke dalam dua kategori, yaitu anggota dan bukan anggota. Pada himpunan tegas (crisp), nilai keanggotaan suatu item $\mathrm{x}$ dalam suatu himpunan $\mathrm{A}$, sering ditulis dengan $\mu \mathrm{A}[\mathrm{x}]$ (Wibowo, n.d.). Fuzzy metode Takagi-Sugeno merupakan metode inferensi fuzzy untuk aturan yang direpresentasikan dalam bentuk IF - THEN (Lamrabet, Ech-charqy, Tissir, \& Haoussi, 2019) dimana output (konsekuen) sistem tidak berupa himpunan fuzzy, melainkan berupa konstanta atau persamaan linear (Civelek, 2019).

Pada perubahan ini, sistem fuzzy memiliki suatu nilai rata-rata tertimbang (Weighted Average Values) di dalam bagian aturan fuzzy IF-THEN. Sistem fuzzy Sugeno juga memiliki 
kelemahan terutama pada bagian THEN, yaitu dengan adanya perhitungan matematika sehingga tidak dapat menyediakan kerangka alami untuk merepresentasikan pengetahuan manusia dengan sebenarnya (Ayuningtias, 2017). Permasalahan kedua adalah tidak adanya kebebasan untuk menggunakan prinsip yang berbeda dalam logika fuzzy, sehingga ketidakpastian dari sistem fuzzy tidak dapat direpresentasikan secara baik (Meimaharani, Listyorini, 2014).

Langkah-langkah penelitian meliputi pengumpulan data, identifikasi data untuk menentukan variabel dan semesta pembicaraan yang diperlukan dalam melakukan perhitungan dan analisis masalah. Proses pengolahan data meliputi proses fuzifikasi, pembentukan aturan dasar, komposisi aturan, defuzifikasi, dan pengujian (Suwardi, Irawan, \& Mukhlash, 2011). Sugeno-jenis FIS menggunakan rata-rata tertimbang untuk menghitung output, sehingga fungsi keanggotaan output Sugeno ini adalah baik linier atau konstan (Blej \& Azizi, 2016).

Untuk itu penelitian ini dilakukan untuk mempermudah wisatawan dalam menentukan jalur optimal yang ada di Surabaya. Fuzzy Sugeno dipilih karena Fuzzy Sugeno merupakan suatu model pendukung keputusan yang mampu memberikan output yang lebih optimal dalam memilih jalur terbaik untuk menuju lokasi wisata yang ada di Kota Surabaya dibandingkan logika yang lain. Penelitian ini akan diimplementasikan dalam aplikasi yang dirancang dalam pemrograman matlab.

\section{METODE}

Dalam penelitian ini, perhitungan fuzzy sugeno dilakukan untuk menentukan jalur terbaik menuju lokasi wisata di Surabaya. Dibutuhkan tiga variabel input diantaranya jarak, waktu, dan kepadatan jalan. Dalam data ini terdapat 54 data dengan dua output yaitu optimal dan kurang optimal. Data diambil dari google maps dari tiga titik pusat (Balaikota Surabaya, Terminal Purabaya, dan Pelabuhan Tanjung Perak) dengan tiga jalur yang berbeda dan menuju enam tujuan destinasi tempat wisata diantaranya Tugu Pahlawan, Food Junction Pakuwon, Atlantis Land Surabaya, Kebun Binatang Surabaya (KBS), Suroboyo Carnival, dan Hutan Mangrove.

Aturan dasar fuzzy mendefinisikan hubungan antara fungsi keanggotaan dan bentuk fungsi keanggotaan hasil. Pada metode sugeno output (konsekuen) sistem tidak berupa himpunan fuzzy tetapi berupa konstanta atau persamaan linier (Suwardi et al,. 2011). Fuzzifikasi merupakan proses mentransformasikan data pengamatan ke dalam bentuk himpunan fuzzy. Dalam penelitian ini metode fuzzy menggunakan orde nol. Secara umum bentuk fuzzy sugeno orde nol adalah:

$$
\text { IF } \left.\left(x_{1} \text { is } A_{1}\right) o\left(x_{2} \text { is } A_{2}\right) \text { o... ( } x_{N} \text { is } A_{N}\right) \text { THEN } z=k
$$

Dengan $A_{i}$ adalah himpunan fuzzy ke- $i$ sebagai anteseden dan $\mathrm{k}$ adalah konstanta tegas sebagai konsekuen. membentuk fungsi implikasi. Aturan-aturan dibentuk untuk menyatakan relasi antara input dan output. Operator yang digunakan untuk menghubungkan antara dua input adalah operator AND dan yang memetakan antara input-output adalah IF-THEN.

Apabila sistem terdiri dari beberapa aturan, maka inferensi diperoleh dari kumpulan dan korelasi antar aturan yaitu menghitung hasil dari $\sum_{r=1}^{R} \alpha_{r} z_{r}$ dengan R banyaknya rule, $\alpha_{r}$ firestrength ke-r, dan $z_{r}$ output pada anteseden aturan ke-r.

Proses defuzzifikasi, pada proses ini output berupa bilangan crisp yang merupakan hasil akhir dari sistem fuzzy. Defuzzifikasi dilakukan dengan cara mencari nilai rata-ratanya yaitu $z=\frac{\sum_{r=1}^{R} \alpha_{r} z_{r}}{\sum_{r=1}^{R} \alpha_{r}}$

Kemudian dari jalur-jalur diproses berdasarkan aturan dari fungsi implikasi yang telah dibuat sehingga didapatkan hasil jalur yang optimal. 


\section{HASIL DAN PEMBAHASAN}

Pembahasan diperlukan untuk mengetahui hasil dari penelitian sudah dapat menyelesaikan permasalahan atau belum. Permasalahan yang telah dirumuskan sebelumnya yaitu apakah metode Fuzzy Inference System Takagi-Sugeno-Kang (metode Sugeno) dapat menentukan pemilihan jalur terbaik menuju lokasi wisata di Surabaya. Input diperoleh dengan menggunakan permasalahan yang ada di jalur menuju wisata diantaranya jarak yang ditempuh, waktu, dan kepadatan jalan.

Tabel1. Penentuan Input dan Output

\begin{tabular}{|c|c|c|}
\hline Fungsi & Variabel & Range \\
\hline Input & $\begin{array}{c}\text { Jarak } \\
\text { Waktu } \\
\text { Kepadatan Jalan }\end{array}$ & $\begin{array}{l}{\left[\begin{array}{ll}0 & 24\end{array}\right]} \\
{\left[\begin{array}{ll}0 & 60\end{array}\right]} \\
{\left[\begin{array}{ll}0 & 24\end{array}\right]}\end{array}$ \\
\hline Output & Keputusan & {$\left[\begin{array}{ll}0 & 1\end{array}\right]$} \\
\hline
\end{tabular}

Setelah ditentukan input dan output, maka langkah selanjutnya menentukan aturan fuzzy dengan metode Sugeno. Untuk mendapatkan nilai output dari pendapatan akhir dengan aturan fuzzy Sugeno dilakukan dengan pembentukan himpunan fuzzy dan derajat keanggotaannya (fuzzifikasi), penentuan rules, penalaran (inferensi) dan defuzzifikasi (defuzzification) (Irawan, 2017).

Tabel 2. Himpunan Fuzzy

\begin{tabular}{|c|c|c|}
\hline Tabel & Himpunan & Domain \\
\hline Jarak & $\begin{array}{c}\text { Dekat } \\
\text { Sedang } \\
\text { Jauh }\end{array}$ & $\begin{array}{c}{\left[\begin{array}{ll}0 & 8\end{array}\right]} \\
{\left[\begin{array}{ll}6 & 18\end{array}\right]} \\
{\left[\begin{array}{ll}16 & 24\end{array}\right]}\end{array}$ \\
\hline Waktu & $\begin{array}{c}\text { Cepat } \\
\text { Sedang } \\
\text { Lama }\end{array}$ & $\begin{array}{c}{\left[\begin{array}{ll}0 & 20\end{array}\right]} \\
{\left[\begin{array}{ll}10 & 50\end{array}\right]} \\
{\left[\begin{array}{ll}40 & 60\end{array}\right]}\end{array}$ \\
\hline $\begin{array}{l}\text { Kepadatan } \\
\text { Jalan }\end{array}$ & $\begin{array}{c}\text { Lancar } \\
\text { Sedang } \\
\text { Macet }\end{array}$ & $\begin{array}{c}{\left[\begin{array}{ll}0 & 8\end{array}\right]} \\
{\left[\begin{array}{ll}6 & 18\end{array}\right]} \\
{\left[\begin{array}{ll}16 & 24\end{array}\right]}\end{array}$ \\
\hline
\end{tabular}

1) Fuzzyfikasi

Tahapan ini merupakan tahapan untuk mengubah variabel numerik (variabel non fuzzy) berupa bobot nilai, batas interval minimum dan maksimum dari gejala yang dipilih menjadi variabel linguistik (variabel fuzzy) dengan rumus fuzzyfikasi sehingga didapatkan nilai fuzzy (Setiawati, Budiman, \& Soesanto, 2016). Himpunan fuzzy dan derajat keanggotaan (member function) yang digunakan pada tiap variabel fuzzy ditentukan berdasarkan data dari variabel (Tabel 2). Contoh proses fuzzyfikasi dalam input jarak yaitu: 


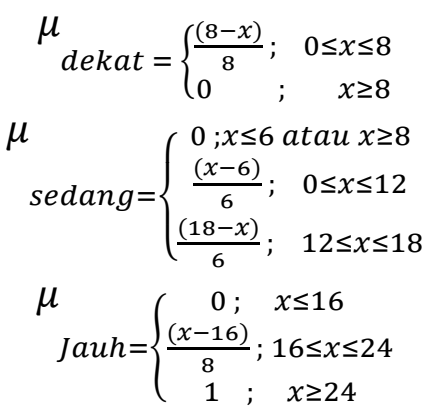

Lalu masukkan nilai $x=5,5$ ke dalam proses fuzzyfikasi maka diperoleh hasil 0,31 . Jadi hasil nilai untuk jarak $5,5 \mathrm{~km}$ adalah 0,75.

2) Aplikasi fungsi implikasi

Penentuan rules didasarkan pada pengujian secara manual dengan memperhitungkan probabilitas kemungkinan yang terjadi dengan kombinasi variabel. Contoh pembentukan aturan premis pada sistem ini yaitu IF dekat AND cepat AND lancar THEN Optimal. Berdasarkan aturan yang telah dibentuk pada tahap akuisisi pengetahuan, didapatkan sebanyak 27 aturan.

Setelah aturan dibentuk, maka dilakukan aplikasi fungsi implikasi. Pada fungsi implikasi yang digunakan adalah MIN, yang berarti tingkat keanggotaan yang didapat dari proses ini adalah nilai minimum dari variabel-variabel yang dibentuk. Sehingga didapatkan daerah fuzzy pada variabel keputusan untuk masing-masing aturan. Pada metode Sugeno tidak semua kemungkinan aturan dipakai, namun hanya aturan yang mungkin saja yang dipakai dalam penentuan jalur terbaik wisata di Surabaya .

\section{3) Defuzzifikasi}

Tahapan ini merupakan tahapan akhir dari logika fuzzy dimana setelah dilakukan fuzzyfikasi pada tiap jalur yang dipilih, kemudian dari jalur-jalur tersebut diproses berdasarkan aturan dari fungsi implikasi yang telah dibuat sehingga didapatkan jalur terbaik yang akan dilewati. Misal apabila wisatawan berada pada titik awal Balaikota Surabaya dengan tujuan Atlantis Land Surabaya, jalurjalur yang dapat dilewati: Jl. Jaksa Agung - Jl. Pacarkeling - Jl. Kenjeran, jika jarak = 8,9 km , waktu $=24$, dan kepadatan jalan $=0,1$. Kemudian dilakukan perhitungan defuzzifikasi dengan rumus ratarata (average). Pada tahap ini adalah menentukan variabel linguistik keputusan dari setiap rule yang telah dibuat. Berikut adalah variabel linguistik untuk jalur tempuh dari setiap rule. Kurang Optimal memiliki nilai $=0$ dan Optimal memiliki nilai $=1$.

Dari pengujian dari Terminal Purabaya ke Tugu Pahlawan. Sebagai contoh yaitu: Input dari Terminal Purabaya ke Tugu Pahlawan.
a. Jarak yang ditempuh $=13,3 \mathrm{~km}$
b. Waktu $=19$ menit
c. Kepadatan jalan $=1,25 \mathrm{~km}$

Dari hasil tersebut bahwa nilai yang dihasilkan adalah 1 yaitu menandakan hasil jalur pilihan optimal. 
Tabel 3. Hasil dari Penentuan Jalur Terbaik

\begin{tabular}{cccccc}
\hline Tempat wisata & Jalur & $\begin{array}{c}\text { Jarak } \\
(\mathbf{k m})\end{array}$ & $\begin{array}{c}\text { Waktu } \\
\text { (menit) }\end{array}$ & $\begin{array}{c}\text { Kepadatan } \\
\text { Jalan }(\mathbf{k m})\end{array}$ & Keputusan \\
\hline \multirow{3}{*}{ Tugu Pahlawan } & 1 & 13,3 & 19 & 1,25 & 0 \\
& 2 & 17,3 & 42 & 6,25 & KO \\
& 3 & 18 & 52 & 2,5 & $\mathrm{KO}$ \\
\hline \multirow{3}{*}{ Food Junction } & 1 & 21,4 & 41 & 5 & $\mathrm{KO}$ \\
& 2 & 18,8 & 42 & 5 & $\mathrm{KO}$ \\
& 3 & 14 & 18 & 2,5 & 0 \\
\hline \multirow{2}{*}{ KBS } & 1 & 17,7 & 54 & 1,25 & $\mathrm{KO}$ \\
& 2 & 15,9 & 49 & 11,25 & $\mathrm{KO}$ \\
& 3 & 7 & 16 & 3,25 & 0 \\
\hline \multirow{3}{*}{ Atlantis Land } & 1 & 14,6 & 47 & 7,5 & $\mathrm{KO}$ \\
& 2 & 16,1 & 51 & 10 & $\mathrm{KO}$ \\
& 3 & 8,9 & 24 & 1,25 & 0 \\
\hline \multirow{3}{*}{ SCN } & 1 & 18 & 40 & 6,25 & $\mathrm{KO}$ \\
& 2 & 11 & 26 & 5 & 0 \\
& 3 & 19,4 & 47 & 11,25 & $\mathrm{KO}$ \\
\hline \multirow{3}{*}{ Mangrove } & 1 & 19,7 & 46 & 3,75 & $\mathrm{KO}$ \\
& 2 & 17,4 & 42 & 6,25 & $\mathrm{KO}$ \\
& 3 & 14 & 33 & 3,75 & 0 \\
\hline
\end{tabular}

Dari (Tabel 3) diketahui bahwa O (Optimal) dan KO (Kurang Optimal). Dalam keputusan aplikasi Matlab diasumsikan Optimal $=1$ dan Kurang Optimal $=0$. Seluruh pengujian yang dilakukan sesuai dengan rule yang telah dirancang dengan jalur tempuh yang dihasilkan. Untuk titik awal berada di Terminal Purabaya, Balaikota Surabaya, dan Pelabuhan Tanjung Perak masing-masing ada 18 jalur yang akan dilewati menuju 6 destinasi tempat wisata. Dengan membandingkan tiga jalur yang dilewati (jalur 1, jalur 2, jalur 3) diperoleh keputusan 6 jalur optimal dengan persentasi 33,36\% atau 12 jalur kurang optimal dengan presentase $66,64 \%$. Jadi dapat disimpulkan bahwa metode Fuzzy Inference System Takagi-Sugeno-Kang dapat diterapkan pada penentuan jalur terbaik menuju wisata di Surabaya.

\section{SIMPULAN}

Setelah melakukan penelitian ini dapat dilihat bahwa dalam menentukan pemilihan jalur terbaik menuju lokasi wisata di Surabaya dapat ditentukan dengan logika fuzzy metode Sugeno. Hal ini tergambar dari hasil defuzzyfikasi yang dihasilkan dengan aplikasi yang dirancang menggunakan Aplikasi Matlab dengan perhitungan manual sehingga dapat disimpulkan sebagai berikut.

1. Dengan logika fuzzy mampu memberikan keputusan yang lebih optimal tentang pemilihan jalur terbaik menuju lokasi wisata di Surabaya.

2. Penentuan jalur terbaik wisata di Surabaya dapat menggunakan logika fuzzy metode Sugeno. Fuzzy logic ini mampu mengatasi masalah penetuan jalur terbaik dengan membandingkan 3 jalur di setiap titik awal dan lokasi wisata dengan beberapa kondisi yang memengaruhi yaitu: Jarak, waktu, dan kepadatan jalan. Sehingga di dalam metode ini seseorang dapat melakukan pemilihan jalur terbaik yang akan dilewati untuk menuju lokasi wisata di Surabaya.

3. Dari perhitungan dengan Matlab dan manual diperoleh ada enam jalur yang optimal dengan presentase $33,36 \%$ atau 12 jalur kurang optimal dengan persentase $66,64 \%$. Dengan demikian wisatawan dapat menghindari kemacetan, jarak yang optimal, dan menghemat waktu dalam perjalanan. 


\section{REFERENSI}

Ayuningtias, L.P. (2017). Analisa perbandingan logic fuzzy metode Tsukamoto, Sugeno, dan Mamdani (Studi kasus: Prediksi jumlah pendaftar mahasiswa baru Fakultas Sains dan Teknologi Universitas Islam Negeri Sunan Gunung Djati Bandung).

Bahroini, A., Farmadi, A., \& Nugroho, R.A. (2016). Prediksi permintaan produk mie instan dengan metode fuzzy Takagi-Sugeno. Kumpulan Jurnal IImu Komputer, 3(2): 220-230.

Blej, M., \& Azizi, M. (2016). Comparison of Mamdani-Type and Sugeno-Type fuzzy inference systems for fuzzy real time scheduling. International Jurnal of Applied Engineering Reseacrh, 11(22): 11071-11075.

Civelek, Z. (2019). Optimization of fuzzy logic (Takagi-Sugeno) blade pitch angle controller in wind turbines by genetic algorithm. Engineering Science and Technology, an International Journal (xxxx). Diambil dari website https://doi.org/10.1016/j.jestch.2019.04.010.

Irawan, M.D. (2017). Sistem pendukung keputusan menentukan matakuliah pilihan pada kurikulum berbasis KKNI menggunakan metode Fuzzy Sugeno. Jurnal Media Infotama, 13(1): 27-35.

Kurnia, D., \& Kesumaningtyas, F. (2017). Penerapan fuzzy logic dalam pencarian jalur terbaik menuju lokasi wisata di Kota Bukittinggi. Jurnal Teknoif, 5(2): 1-7.

Lamrabet, O., Ech-charqy, A., Tissir, E.H., \& Haoussi, F.E.L. (2019). Science direct sampled data control for Takagi-Sugeno fuzzy systems with actuator saturation. Procedia Computer Science, 148 (Icds 2018): 448-454. Diambil dari website https://doi.org/10.1016/ j.procs.2019.01.057.

Meimaharani, R., \& Listyorini, T. (2014). Analisis sistem inference fuzzy Sugeno dalam menentukan harga penjualan tanah untuk pembangunan minimarket. Jurnal Teknik Industri, Mesin, Elektro dan Ilmu Komputer, 5(1): 89-96.

Samita, S., Bihari, B., \& Samanta, S. (2018). Competency mapping with Sugeno Fuzzy Inference System for variable pay determination : A case study. Ain Shams Engineering Journal, 9(4): 2215-26. Diambil dari website https://doi.org/10.1016/j.asej.2017.03.007.

Suwardi, S., Irawan, M.I., \& Mukhlash, I. (2011). Aplikasi sistem inferensi fuzzy metode Sugeno dalam memperkirakan produksi air mineral dalam kemasan. Lumbung Pustaka Universitas Negeri Yogyakarta.

Setiawati, L. S., Budiman, I., \& Soesanto, D. (2016). Penerapan fuzzy inference system TakagiSugeno-Kang pada sistem pakar diagnosa penyakit gigi. Kumpulan Jurnal Ilmu Komputer, 3(1): 1-10.

Wibowo, S. (n.d). Penerapan logika fuzzy dalam penjadwalan waktu kuliah. 